\title{
The performance of morally questionable shares in South Africa (2004-2019)
}

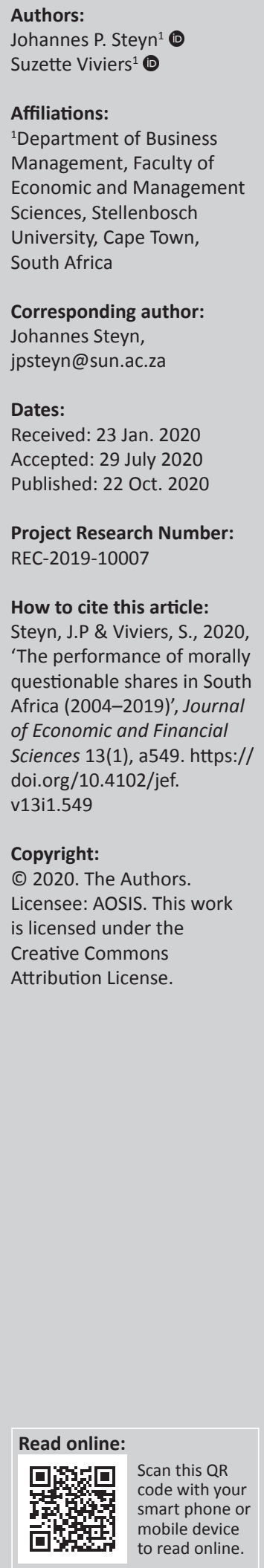

Orientation: Investors are increasingly weighing up the cost of investing in companies with adverse impacts on society and the natural environment.

Research purpose: In light of the shift to responsible investing, this study compared the riskadjusted performance of a portfolio of morally questionable shares listed on the Johannesburg Stock Exchange (JSE) to a portfolio consisting of morally acceptable (responsible) ones.

Motivation for the study: Although previous research suggests that investors can perform well by investing in morally questionable shares (such as alcohol and tobacco), sentiment is rapidly moving towards a more responsible approach to selecting shares.

Research approach/design and method: The historic returns of equity portfolios were evaluated over the period July 2004 to April 2019. Two equally weighted portfolios were constructed: one for morally questionable shares and the other for morally acceptable shares. These portfolios' risk-adjusted returns were compared to the JSE Responsible Investment Composite Index, the Financial Times Stock Exchange/JSE Shareholder Weighted Index and an equally weighted benchmark. In addition, the analysis was divided into two distinct sub-periods, covering the financial crisis and the subsequent recovery period. Morally questionable companies included those with exposure to alcohol, tobacco, gambling, oil, gas and coal.

Main findings: Morally questionable investing in South Africa does not produce risk-adjusted outperformance. No evidence was found to support the theories predicting the outperformance of morally questionable shares on the JSE.

Practical/managerial implications: Socially and environmentally conscious investors can achieve risk-adjusted returns comparable to those of investors who opt to invest in morally questionable shares and conventional benchmarks.

Contribution/value-add: The study provides insights for investors who are concerned about the opportunity costs of adopting a responsible investment approach.

Keywords: vice investing; ethical investing; virtue investing; responsible investing; moral acceptability.

\section{Introduction}

Is it beneficial for an investor, from a risk-adjusted point of view, to invest in morally questionable companies? This question is important given the growing emphasis on investing in a responsible manner (Riedl \& Smeets 2017). Several studies show that investors who are willing to invest in morally questionable shares are able to enjoy higher risk-adjusted returns compared to those who shun these shares (Jo et al. 2010; Vide 2016). Merton's (1987) 'neglected stock theory' could provide a possible explanation for the outperformance. This theory suggests that morally questionable shares could be systematically underpriced because of the lack of institutional investor and analyst coverage. Although views on what could be regarded as bad, morally questionable, unethical or sinful differ (Sparkes 2001), reference is often made to harmful products and services such as tobacco, alcohol, adult entertainment, gambling, weapon manufacturing and nuclear energy (Fabozzi, Ma \& Oliphant 2008; Hong \& Kacperczyk 2009; Lobe \& Walkshäusl 2016; Richey 2016).

The addictive nature of the so-called vice products and services enables companies to maintain consistently high financial returns, even during economic downswings (Jo et al. 2010). Blitz and Fabozzi (2017) propose that the global reach of addictive products, high barriers to entry in most of the 'sin' industries and high margins contribute to abnormal returns. In this study, the term 'morally questionable investing' not only refers to investments in companies producing the harmful products and services listed above but also includes major air polluters 
(such as companies operating in oil, gas and coal sectors) and companies abusing human rights. As will be shown in the literature review, defining moral acceptability is a more complex exercise.

The risk-adjusted performance of a portfolio of morally questionable shares listed on the Johannesburg Stock Exchange (JSE) was compared to a portfolio consisting of morally acceptable shares. The analysis covered the period July 2004 to April 2019. The risk-adjusted returns of the two equally weighted portfolios were compared to the JSE Responsible Investment (RI) Composite Index, the Financial Times Stock Exchange (FTSE)/JSE Shareholder Weighted Index (SWIX) and an equally weighted benchmark (EQBM). The study contributes to the limited body of knowledge on morally questionable investing, particularly in the South African context. Insights gleaned will also clarify questions that investors might have regarding the opportunity costs associated with avoiding morally questionable shares.

Arguments in favour of morally questionable investing are presented next, followed by empirical evidence in this regard. The definition of, and rationale for, morally acceptable investing is then described along with pertinent empirical findings. Attention is also given to morally acceptable (responsible) investing in South Africa.

\section{Arguments supporting morally questionable investing}

There are a number of reasons why a morally questionable investment strategy should outperform a conventional investment strategy. One popular theory, related to the notion of neglected stocks proposed by Merton (1987), refers to morally questionable shares that are expected to outperform because they are systematically underpriced by investors who avoid them. This theory may not be universally applicable. In some markets, like South Africa, vice shares, such as British American Tobacco, are widely covered and held in institutional portfolios. Limits to arbitrage could explain how certain constraints, such as budgetary constraints, could prevent investors not affected by ethical restrictions from fully trading away this effect (Shleifer \& Vishny 1997).

Hong and Kacperczyk (2009) suggested that morally questionable shares should have higher expected returns because of increased litigation risk. Investors require additional compensation for assuming the heightened risk. Headline risk refers to the risk of major negative news about the company becoming public and adversely affecting the share price. The additional risk of being subject to the economic implication of a product boycott or an employee strike should increase the expected return demanded by investors.

Other explanations for the possible outperformance of morally questionable companies are based on economic and psychological reasons. There are often high barriers to entry in 'sin' industries, which result in monopoly type protection of incumbents (Blitz \& Fabozzi 2017). The high cost of research and development in industries such as defence and biotech also acts like a barrier to entry (Fabozzi et al. 2008). In addition, vice industries are often high-margin businesses (Dimson, Marsh \& Staunton 2015). Because of the addictive nature of many morally questionable products (notably alcohol, tobacco and gambling), there is a consistent demand for these products and services regardless of economic conditions. This phenomenon should make the prices of these shares more resilient in bear markets.

\section{Empirical studies on morally questionable investing}

Numerous international studies have been conducted on morally questionable investing, particularly vice investing. In the United States (US), Derwall, Koedijk and Ter Horst (2011); Durand, Koh and Limkriangkrai (2013); Hong and Kacperczyk (2009); Statman and Glushkov (2009); and Kempf and Osthoff (2007) all investigated the performance of vice investing and unilaterally found that vice shares earned abnormal positive returns. This evidence was supported by studies in Europe (Salaber 2007), a multinational study covering 21 countries by Fabozzi et al. (2008) and an analysis of Group of Twenty (G20) countries by Fauver and McDonald (2014). The comprehensive study by Hong and Kacperczyk (2009) investigated 193 US firms over the period 1926 to 2006. Employing a number of methodologies to investigate returns, they found that vice shares managed to generate positive excess returns of between $3 \%$ and $5 \%$.

There appears to be some inconsistency in the literature between the performance of vice-type funds and individual sin shares. Studies investigating the performance of vice-type funds, such as the VICEX Fund, found no evidence of outperformance (Chang \& Krueger 2013; Hoepner \& Zeume 2014). Two different studies have examined the sin share anomaly using the Fama-French five-factor model (Blitz \& Fabozzi 2017; Richey 2017). Both studies found that vice shares generate positive alpha when the capital asset pricing model, the Fama-French three-factor model and the Carhart four-factor model are used. These results suggest abnormal risk-adjusted returns for vice shares, in line with the majority of results from previous studies. However, when the additional two quality factors (profitability and investment) suggested by Fama and French (2015) were added to the evaluation, the alpha's significance disappeared.

The implication of the evidence presented is that the observed outperformance of vice shares can be explained by the two new quality factors. Vice-type shares tend to have high exposure to both factors. Tobacco companies, for instance, typically have higher margins because of their price inelasticity. Additionally, vice companies are restricted in the way they can expand their asset base (Blitz \& Fabozzi 2017). The research suggests that the performance of vice shares is, therefore, in line with conventional asset pricing models, and there is no additional return premium available. 


\section{Defining morally acceptable investing}

The concept of ethical or virtue investing emerged in the 18th century and it describes investments based on moral or religious convictions (Sparkes 2001). Quakers, for example, refused to invest in companies producing alcohol or trading in slaves. As practitioners and scholars in the 1960s objected to using the word 'ethical' to describe their investment approach (Sparkes \& Cowton 2004), other names emerged for the practice of incorporating ethical, and environmental, social and corporate governance (ESG) considerations into investment practices. Prominent names include social investing, socially responsible investing (SRI), green investing, sustainable investing and, more recently, RI.

The launch of the United Nations-backed Principles for Responsible Investment (PRI) in 2005 provided muchneeded clarity for practitioners and scholars. The PRI emphasises the important role that ESG factors could play in determining investment risk and returns (PRI 2019). Given widespread support for the PRI, reference will also be made to RI in this study when referring to morally acceptable investments. A growing number of investors are embracing RI, both globally (Riedl \& Smeets 2017) and in South Africa (Viviers \& Els 2017).

\section{Arguments in favour of responsible investment}

The rationale for adopting an RI strategy is grounded in stakeholder theory, where firms that are involved in positive business activities are said to have a competitive advantage over those that are not (see, e.g. Bénabou \& Tirole 2010; Kitzmueller \& Shimshack 2012). The competitive advantage stems from sources such as increased long-term profitability and the reduction of tail risk. Tail risks are events or outcomes that have a small probability of occurring. These 'outlier' events can be decreased by reducing frictions between the company and society by, for example, avoiding product boycotts or employee strikes (Margolis, Elfenbein \& Walsh 2009). The relative cost saving resulting from not being exposed to litigation, environmental restitution risks or carbon taxes can contribute to higher expected future cash flows. These higher expected cash flows can, in turn, positively affect a company's value.

The information generated by the screening process could be a source of potential outperformance of RI strategies and funds (Renneboog, Ter Horst \& Zhang 2008). This argument, however, requires a certain degree of market inefficiency to deliver excess investment performance.

The errors-in-expectations hypothesis, suggested by Derwall et al. (2011), predicts that RIs can produce superior returns because of the market systematically undervaluing the impact of good governance practices. The authors, however, cautioned that the outperformance could be shortlived as investors may learn to incorporate the potentially positive impact of sustainable business practices in their expectations. On the other hand, one theory for the possible underperformance of screening strategies relates to the relative cost of capital. With an increased corporate awareness of ESG factors generally, companies that identify and manage these risks will attract more capital relative to those that do not. This will lower the responsible company's cost of capital, increase its share price and lead to lower future returns (Hamilton, Jo \& Statman 1993).

$\mathrm{Fu}$ and Shan (2009) posit that RI strategies should underperform fully diversified portfolios because of the constraint the screening process places on the investment opportunity set. This explanation is related to modern portfolio theory where the lack of adequate diversification in RI funds could contribute to lower returns (Barnett \& Salomon 2006). Another line of reasoning is that costs of monitoring and following ESG standards could lead to competitive disadvantage and lower profitability (Walley \& Whitehead 1994). Likewise, Derwall et al. (2011) emphasise that certain socially and environmentally responsible practices are inherently costly at the outset and the related benefits may take a long time to accrue, thus affecting shortterm profitability. Related to the impact of various costs, Bauer, Koedijk and Otten (2005) suggest that the monitoring cost of social performance of investee companies could increase investment management cost, which could contribute to lower returns. More details on the performance of morally screened funds are presented below.

\section{Empirical studies on responsible investment performance}

The potential underperformance of RI funds could be owing to the willingness of socially and environmentally conscious investors to accept lower returns. Fu and Shan (2009) argue that RI-focussed investors would tolerate lower investment returns because they derive non-financial utility from holding certain socially and environmentally responsible shares. On the other hand, stakeholder theory suggests that companies involved in more sustainable activities would be at a longterm competitive advantage and, therefore, may generate higher share returns (see, e.g. Bénabou \& Tirole 2010; Kitzmueller \& Shimshack 2012; Margolis et al. 2009).

Internationally, numerous studies investigated the performance of RI strategies (see, e.g. Bauer et al. 2005; GilBazo, Ruiz-Verdú \& Santos 2010; Girard, Rahman \& Stone 2007; Hamilton et al. 1993; Nofsinger \& Varma 2014; Shank, Manullang \& Hill 2005; Statman 2000). The evidence appears inconclusive, with a number of studies reporting that RI underperforms conventional strategies (Frost et al. 2005; Girard et al. 2007), a few studies presenting evidence of RI outperformance (Fu \& Shan 2009; Gil-Bazo et al. 2010; Knoepfel 2001) and many findings showing that RI returns were no different from conventional strategies (Bauer et al. 2005; Hamilton et al. 1993; Nofsinger \& Varma 2014). Other studies compared the performance of sin-themed investment strategies against RI strategies (notably Fabozzi et al. 2008; Hong \& Kacperczyk 2009; Richey 2016; Salaber 2009, Vide 2016). The majority of these studies found that sin-themed shares earned positive abnormal returns. 
Investigating the relative performance of RI strategies on a fund and index level has been an increasingly popular topic amongst international researchers. This trend is possibly because of an increased awareness of sustainability issues amongst investors (Renneboog et al. 2008). In addition, the contradicting theoretical expectations alluded to earlier raise alluring empirical questions. A number of studies have been carried out to compare the risk-adjusted returns of RI funds to conventional funds or indices. Many of these studies found that there was no difference in the return generated between an RI fund and a conventional fund (Bauer, Derwall \& Otten 2007; Nofsinger \& Varma 2014; Shank et al. 2005; Statman 2000, 2006). Some studies did, however, report RI outperformance during crisis periods (Lins, Servaes \& Tamayo 2017; Nofsinger \& Varma 2014). One reason might be that sound management of ESG risks could point to good management practices overall.

Evidence that RI underperformed conventional funds was provided by Frost et al. (2005) and Schröder (2007). Gil-Bazo et al. (2010) specifically investigated the role played by fund managers in determining the financial performance of RI funds. The authors reported underperformance by funds that are run by management companies not specialised in RI. However, firms that specialise in RI strategies managed to produce after-fee performance that is higher than that of matched conventional funds.

Relatively few studies have supported RI strategy outperformance. On an index level, Knoepfel (2001) compared the Dow Jones Global World Index to the Dow Jones Sustainability Group World Index. It was found that the sustainability index outperformed the regular equity index in terms of average return on equity. Kempf and Osthoff (2007) showed that a share selection strategy of choosing companies with high RI ratings, and selling shares with poor RI ratings, could produce abnormal positive returns. Importantly, the positive outperformance was generated after taking into consideration the impact of transaction costs.

Very few RI studies have been conducted in South Africa. One reason could be the small RI investment universe. A brief overview of the local RI market is presented next along with the findings of three empirical studies.

\section{Morally acceptable (responsible) investing in South Africa}

Local trade unions became the first responsible investors in the country when they refused to invest their members' funds in companies that were supportive of the apartheid government (Herringer, Firer \& Viviers 2009). The pace of adoption was, however, very slow until the JSE introduced its SRI Index in 2004 (Viviers \& Els 2017). This index was later replaced by the FTSE/JSE RI Index in 2015 (JSE 2019). Both indices are positive screening indices as they include companies based on positive sustainability criteria. Neither of the indices excludes conventional vice shares. The JSE
SRI Index's initial inclusion criteria focussed on environmental, economic and social sustainability, as well as good corporate governance (JSE 2004). With the introduction of the FTSE/JSE RI Index in 2015, the FTSE Russell ESG ratings and data scoring model were adopted (JSE 2019).

Although the new scoring mechanism is more comprehensive, the three essential ESG pillars' criteria were maintained. Companies that generate high scores are typically those that demonstrate that they have policies and practices in place to measure and monitor ESG risk exposures. A mining company can thus be included if there is a clear policy in place to address environmental issues. Although important, the actual environmental impact of a company's activities plays a less prominent role.

On a fund level, Viviers and Firer (2013) investigated the performance of 16 RI unit trust funds from 1992 to 2006. The risk-adjusted performance of these funds was compared to the performance of their stated benchmarks and the FTSE/JSE All Share Index. Although no outperformance of RI funds was noted over the entire sample period, the funds significantly outperformed their benchmarks during the latter part of the sample period (2002-2006).

Chawana (2014) compared the performance of the JSE SRI Index to local market indices from 2004 to 2012. Evidence was presented of risk-adjusted underperformance of the JSE SRI Index in both bull and bear market conditions. It was suggested that the observed underperformance was owing to the constrained investable universe and consequent lack of diversification in the SRI strategy. Similarly, Gladysek and Chipeta (2012) showed that the only calendar year that the JSE SRI Index outperformed the FTSE/JSE All Share Index was 2004. Importantly, the authors used a sample period that started in May 2004, to line up with the introduction of the JSE SRI Index.

\section{Research objectives}

To address the gap in the literature, the primary objective of this study centred on the risk-adjusted performance of a portfolio of morally questionable JSE-listed shares relative to a portfolio consisting of morally acceptable (responsible) shares. Three secondary objectives were formulated. The first objective was to determine whether morally questionable shares outperformed morally acceptable shares after accounting for risk. The second objective was to establish whether either morally questionable or morally acceptable shares outperformed a composite RI Index. The third objective was to compare the risk-adjusted performance of morally acceptable and morally questionable portfolios to a broad market index (SWIX) and an EQBM. In this study, a 'morally acceptable' company was regarded as one that scored high on ESG considerations, but excluded all morally questionable and mining shares. 
Seven null hypotheses were developed to address the research objectives, namely:

$\mathbf{H}_{01}$ : There is no difference between the mean monthly returns of the morally questionable portfolio and the morally acceptable portfolio.

$\mathbf{H}_{02}$ : There is no difference between the risk-adjusted returns of the morally questionable portfolio and the morally acceptable portfolio.

$\mathbf{H}_{03}$ : There is no difference between the risk-adjusted returns of the morally questionable portfolio and the RI Composite Index.

$\mathbf{H}_{04}$ : There is no difference between the risk-adjusted returns of the morally questionable portfolio and the SWIX.

$\mathbf{H}_{05}$ : There is no difference between the risk-adjusted returns of the morally questionable portfolio and the EQBM.

$\mathbf{H}_{06}$ : There is no difference between the risk-adjusted returns of the morally acceptable portfolio and the SWIX.

$\mathbf{H}_{07}$ : There is no difference between the risk-adjusted returns of the morally acceptable portfolio and the EQBM.

\section{Research design and methodology}

The data collection and the sample description, the portfolio construction process and data analysis are explained.

\section{Data collection}

This study compared the performance of morally questionable and morally acceptable shares to each other, and to a number of benchmarks from July 2004 to April 2019. The research period started in 2004 as both the JSE RI Index and the SWIX were launched during that year. Price data were collected from the Bloomberg database.

Monthly total returns were calculated using adjusted prices. The collected price data were adjusted to reflect the impact of dividends, share splits and share buybacks on share returns. The sample frame for this study was the SWIX Index constituents. The SWIX Index is a popular, broad equity market index where the market capitalisation weights are adjusted to reflect the available free float (JSE 2014). Applying these criteria produces an index that is reflective of the investment opportunity set for South African investors. A judgemental, non-probabilistic sampling technique was employed to form the morally questionable and morally acceptable portfolios.

Companies in sectors such as alcohol, tobacco, gambling, military, nuclear power and adult entertainment were considered vice stocks in previous research conducted on vice investing (Fabozzi et al. 2008; Hong \& Kacperczyk 2009; Jo et al. 2010; Richey 2016). To create the morally questionable portfolio, this definition was expanded to include companies with exposure to the mining, beneficiation and utilisation of coal. The environmental degradation and detrimental health effects of these activities are directly in contrast with generally accepted ESG factors. Air pollution from coal-fired power plants is linked to asthma, cancer, heart and lung ailments, neurological problems, acid rain, global warming, and other severe environmental and public health impacts (Ratshomo \& Nembahe 2016).

In addition, during the chemical process that enables coal to produce energy, a number of pollutants harmful to the environment, as well as public health, are produced (World Health Organisation 2017). The listed equity opportunity set in South Africa has limited or no exposure to military, nuclear power and adult entertainment industries (apart from gambling). Therefore, including these sectors in the definition of $\sin$ for selection criteria had no impact on the ultimate portfolio composition.

At the start of each month, all shares that met the morally questionable criteria were included in the morally questionable portfolio for that month. Thereafter, the equally weighted total return was calculated and recorded for the particular month. The process was repeated for the entire sample period, which avoided any potential lookahead or survivorship bias. Qualifying shares listed during a specific month were included in the following month at the closing share price on the last trading day of the month. Shares that were delisted or suspended during the sample period were removed from the portfolio at the closing price on the day of the delisting or suspension.

The morally acceptable portfolio was compiled by using the constituents of the SRI Index (up to October 2015) and the RI Index (from November 2015 to April 2019) as the sampling frame. In doing so, the selection criteria of these indices were indirectly applied. This meant that the reduced sampling frame only contained shares with high ESG scores. Derwall et al. (2004:52) argued that SRI fund studies 'cannot establish whether a social or environmental responsibility premium exists given that social and conventional fund holdings are not mutually exclusive'. To address this critique, and to ensure mutually exclusive portfolios, any shares that were included in the morally questionable portfolio were excluded from the morally acceptable portfolio. Companies would therefore be classified as 'morally acceptable' if they have sustainable business practices in all three ESG areas, and are not included in the definition of 'morally questionable'.

In addition, all mining shares were removed from the portfolio. This was performed to exclude any firms that met the RI selection criteria, but could potentially contribute to environmental degradation because of their business activities. Giamporcaro and Pretorius (2012) noted that responsible investors in South Africa lagged behind their international peers as far as integrating environmental criteria into investment decision processes is concerned. By removing mining shares, a greater emphasis is placed on the environmental aspect, which arguably increases the RI features of the morally acceptable portfolio.

For the morally acceptable portfolio to be a comparable portfolio to the morally questionable portfolio, a matchedsample procedure was utilised. This was performed to avoid any potential return differences because of 
inconsistencies in portfolio concentration and diversification. For any given month, the same number of shares as in the morally questionable portfolio was included in the morally acceptable portfolio. If the morally questionable portfolio included only 18 shares for a given month after applying the screening criteria for selection, then only the largest 18 shares in the morally acceptable sample were included in the morally acceptable portfolio. This process was used to provide a more comparable portfolio to address the intended research objective.

Data were also collected on a number of benchmarks. As indicated earlier, the JSE introduced its SRI Index in May 2004 and replaced it with the FTSE/JSE RI Index in October 2015. To have an RI reference index over the entire research period, a composite return series comprising of both indices was used. The composite index return history is simply the return of the SRI Index up to October 2015 and the RI Index for the period thereafter. This index will be referred to as the RI Composite Index in the remainder of this article.

The SWIX Index was selected as the broad market index, given its popularity as an equity fund benchmark in South Africa. The SWIX Index methodology adjusted the market capitalisation approach used for the FTSE/JSE All Share Index by making adjustments to weighting based on the available free float (JSE 2014). This modification introduced better diversification and was an improved representation of the available opportunity set for South African equity investors.

In addition to comparing the morally questionable and morally acceptable portfolios to the SWIX and RI Composite Index, an EQBM Index was also computed. Both the morally questionable and morally acceptable portfolios were calculated using an equally weighted methodology; therefore, it was necessary to have an additional benchmark that employed the same portfolio construction methodology. Observed performance differences could be because of the way indices were constructed. Both the SWIX and SRI indices follow a market capitalisation weighted methodology. This method causes larger capitalisation shares to have a larger weight in the index and, therefore, a larger impact on the calculated performance of the index. In the calculation of the performance of the EQBM, each share in the opportunity set had an equal contribution to monthly performance.

The Alexander Forbes Short-Term Fixed Interest (STeFI) Composite Index was considered to be an appropriate proxy of the risk-free rate. The STeFI is a proprietary index that measures the performance of money market or short-term fixed interest instruments in South Africa. Only investment instruments with a maximum term of 1 year are eligible for inclusion.

\section{Data analysis}

To address the first hypothesis, a paired sample test (student's $t$-test) on the mean monthly returns was performed. To test whether the monthly returns of both the morally questionable and morally acceptable portfolios were normally distributed, the Jarque-Bera test was employed. Where data samples were not normally distributed, a bootstrapping process was applied to obtain symmetrical distributions on which parametric tests can be performed (Efron \& Tibshirani 1993). The bootstrap process involved resampling up to 5000 times, with replacement from the same group. The resultant distribution thus provided a more accurate estimate of the sample statistic (mean). A summary statistic and accompanying $p$-value could then be calculated based on the bootstrapping procedure.

Observed higher returns can be because of higher risk. It was, therefore, necessary to calculate the risk-adjusted returns for each portfolio. The Sharpe ratio was used to measure and compare risk-adjusted returns. The Sortino ratio was employed as an additional risk-adjusted return measure. The Sortino ratio offers an improvement to the Sharpe ratio by using an alternative risk measure. Where the Sharpe ratio uses the standard deviation as the risk metric, the Sortino ratio employs downside deviation (Sortino \& Van der Meer 1991). This is an improvement as standard deviation does not distinguish between upside or downside volatility. Downside deviation measures the variation of returns below a minimum acceptable return. Following Viviers and Firer (2013), the minimum acceptable return used in this study was zero because rational investors are typically averse to negative returns. Similar to the Sharpe ratio, investors prefer a high Sortino ratio.

To determine whether the risk-adjusted returns of two portfolios were significantly different (hypotheses $\mathrm{H}_{02}$ to $\mathrm{H}_{07}$ ), the Jobson and Korkie (1981) test with the Memmel (2003) correction was employed. The difference between the two Sharpe ratios was tested for statistical significance. This test statistic follows a normal distribution and was calculated using Equation 1.

$$
z=\frac{S R_{1}-S R_{2}}{\sqrt{\frac{1}{n}\left[2\left(1-\rho_{1,2}\right)+\frac{1}{2}\left(S R_{1}^{2}+S R_{2}^{2}-S R_{1} S R_{2}\left(1+\rho_{1,2}^{2}\right)\right)\right]}}
$$

Where:

$S R_{1}=$ the Sharpe ratio of portfolio 1

$S R_{2}=$ the Sharpe ratio of portfolio 2

$\rho_{1,2}=$ the correlation between portfolios 1 and 2

$n=$ the number of observations.

A significance level ( $p$-value) of 0.05 was used to determine statistical significance throughout the study.

\section{Ethical consideration}

This article followed all ethical standards for carrying out research without direct contact with human or animal subjects. 


\section{Results}

The first part of this section presents descriptive statistics and the results of the tests for symmetrical distributions. The second part contains the results of the paired sample test on mean monthly returns. In the third segment, the risk-adjusted returns and tests for significant differences are shown. Then, the performance of the portfolios and the benchmarks are considered in both bear and bull market conditions. Finally, the results are reconciled with the stated hypotheses.

\section{Performance of the morally questionable and morally acceptable portfolios}

Table 1 presents a number of descriptive statistics that show the performance of the morally questionable and morally acceptable portfolios relative to the three benchmarks.

The morally acceptable portfolio generated the highest absolute arithmetic monthly mean (1.59\%), geometric monthly mean $(1.50 \%)$ and compounded annual return (19.53\%) amongst portfolios compared. In addition, it also recorded the best maximum monthly return. This result would suggest that morally acceptable shares could produce outperformance on an absolute return basis. The RI Composite Index produced the lowest returns when considering arithmetic mean (1.15\%), geometric mean $(1.04 \%)$ and compounded annual return (13.21\%). This relative underperformance of the RI Index is consistent with evidence presented in previous South African studies (Chawana 2014; Gladysek \& Chipeta 2012).

The EQBM had the lowest monthly standard deviation $(3.44 \%)$ and the lowest downside deviation (1.88\%). An equally weighted index is more diversified and less concentrated than strategies that employ ESG screens. This result was thus in line with expectations suggested by the literature (Barnett \& Salomon 2006).
Before any test for significant differences could be performed, it had to be established whether the various return streams were symmetrically distributed. The paired sample test and the Sharpe ratio assume that samples are drawn from normal distributions (Jobson \& Korkie 1981). Table 2 presents information about the different return distributions.

A skewness and excess kurtosis score of close to zero would be an indication of a normal distribution (Webster 1995). The morally acceptable portfolio had a skewness and kurtosis score closest to zero, i.e. of -0.02 and 0.32 , respectively. To test whether distributions were symmetrical, the Jarque-Bera test was employed. This test for normality tests the null hypothesis that the sample was drawn from a normal distribution (Jarque \& Bera 1980). A high Jarque-Bera statistic and a significance level below 0.05 would lead to the rejection of the null hypothesis.

From Table 2 it can be seen that only the morally acceptable portfolio and the SWIX had monthly return distributions that were considered symmetrical at the $5 \%$ significance level. To calculate risk-adjusted returns and conduct parametric inferential analysis, it was necessary to conduct a bootstrapping procedure.

\section{Comparing morally questionable returns to morally acceptable returns}

The primary objective of the study was to determine whether morally questionable shares outperformed morally acceptable shares over the research period. Table 3 shows the results of the paired sample test that was employed to determine whether the observed difference in the mean returns was statistically significant. The test was performed after the bootstrap procedure was completed.

TABLE 1: Descriptive statistics: July 2004 to April 2019

\begin{tabular}{|c|c|c|c|c|c|}
\hline Variables & $\begin{array}{l}\text { Morally questionable } \\
\text { portfolio (\%) }\end{array}$ & $\begin{array}{c}\text { Morally acceptable } \\
\text { portfolio (\%) }\end{array}$ & RI Composite Index (\%) & EQBM (\%) & SWIX (\%) \\
\hline Arithmetic mean monthly & 1.56 & 1.59 & 1.15 & 1.29 & 1.21 \\
\hline Geometric mean monthly & 1.44 & 1.50 & 1.04 & 1.23 & 1.13 \\
\hline Median monthly return & 1.78 & 1.57 & 1.60 & 1.44 & 1.49 \\
\hline Maximum monthly return & 11.55 & 14.64 & 12.85 & 10.03 & 10.38 \\
\hline Minimum monthly return & -16.48 & -12.67 & -15.19 & -11.28 & -12.69 \\
\hline Standard deviation of monthly returns & 4.77 & 4.28 & 4.66 & 3.44 & 4.02 \\
\hline Downside deviation of monthly returns & 2.81 & 2.21 & 2.85 & 1.88 & 2.34 \\
\hline Annualised standard deviation & 16.52 & 14.81 & 16.16 & 11.91 & 13.91 \\
\hline Compounded annual return & 18.78 & 19.53 & 13.21 & 15.75 & 14.45 \\
\hline
\end{tabular}

RI, responsible investment; EQBM, equally weighted benchmark; SWIX, Shareholder Weighted Index.

TABLE 2: Tests for normality of distributions.

\begin{tabular}{|c|c|c|c|c|c|}
\hline Variables & Morally questionable portfolio & Morally acceptable portfolio & RI Composite Index & EQBM & SWIX \\
\hline Skewness & -0.53 & -0.02 & -0.37 & -0.35 & -0.31 \\
\hline Excess kurtosis & 1.11 & 0.32 & 0.90 & 0.92 & 0.54 \\
\hline Jarque-Bera statistic & 17.51 & 0.78 & 10.06 & 10.05 & 4.99 \\
\hline Significance & 0.00 & 0.68 & 0.01 & 0.01 & 0.08 \\
\hline Conclusion & Not normal & Normal & Not normal & Not normal & Normal \\
\hline
\end{tabular}

RI, responsible investment; EQBM, equally weighted benchmark; SWIX, Shareholder Weighted Index. 
The mean monthly return of the morally acceptable portfolio was only marginally higher than that of the morally questionable portfolio. However, the paired sample test produced a significance of 0.9140 , which means that the null hypothesis $\left(\mathrm{H}_{01}\right)$ of no difference in observed returns could not be rejected at the 5\% significance level. Stated differently, there was no statistically significant difference between the mean monthly returns of the morally questionable and morally acceptable portfolios.

\section{Risk-adjusted returns}

Two different risk-adjusted return measures were used to compare the performance of the morally questionable and morally acceptable portfolios to the three benchmarks. Table 4 displays the Sharpe ratio and the Sortino ratio calculated for the full research period.

The morally acceptable portfolio generated the highest Sharpe (0.82) and Sortino (0.45) ratios, which suggests that there are few opportunity costs associated with investing responsibly. However, the lowest risk-adjusted statistics were produced by the RI Composite Index, that is, 0.36 and 0.20 for the Sharpe and Sortino ratios, respectively. This apparent discrepancy may be because of the additional criteria imposed to form the morally acceptable portfolio. In addition, the RI Composite Index followed a market capitalisation weighted construction methodology, whereas the morally acceptable strategy was equally weighted. Lastly, the morally acceptable portfolio included 18 shares on average, whereas the SRI Index had in excess of 70 constituents on average. These factors could have had an impact on the performance differences observed.

The morally questionable portfolio had very similar riskadjusted results to the EQBM. This observation could suggest that there is no morally questionable risk premium available on the JSE. Investors not constrained by RI mandates will thus not be better off by following a morally questionable strategy.

The Sharpe and Sortino ratios produced the same relative rankings between the different sets of returns. The Sortino ratio uses downside deviation as the risk-adjustment measure. In certain circumstances, where portfolios have favourable positive volatility, the Sharpe and Sortino ratios can come to different conclusions. The identical relative rankings, shown in Table 4 , indicate that there is perhaps no additional benefit of using the Sortino ratio and that the Sharpe ratio can be used to compare riskadjusted returns.

To address the secondary research objectives (hypotheses $\mathrm{H}_{02}$ to $\mathrm{H}_{07}$ ), tests for statistically significant differences in observed Sharpe ratios were performed. Table 5 presents the results of comparing the Sharpe ratio to that of the morally questionable and morally acceptable portfolios.

As can be seen from Panel A in Table 5, only the RI Composite Index produced a Sharpe ratio that was significantly different from that of the morally questionable portfolio. The morally questionable portfolio outperformed the RI Composite Index on a risk-adjusted basis, but there was no evidence that the morally questionable portfolio outperformed the morally acceptable portfolio. This is in line with results presented by Li, Cheung and Roca (2010). This result would suggest that there is no additional opportunity cost to investing responsibly compared to morally questionable investing. The morally questionable and morally acceptable strategies were both equally weighted portfolios, which had relatively few shares (18 on average). The similar performance observed could be because of portfolio construction effects.

TABLE 3: Paired sample statistics.

\begin{tabular}{|c|c|c|c|c|}
\hline \multirow[t]{2}{*}{ Variable } & \multirow[t]{2}{*}{ Mean or standard deviation } & \multirow[t]{2}{*}{ Statistic } & \multicolumn{2}{|c|}{$95 \%$ confidence interval } \\
\hline & & & Lower & Upper \\
\hline \multirow[t]{2}{*}{ Morally questionable } & Mean & 0.0154 & 0.0081 & 0.0228 \\
\hline & Standard deviation & 0.0481 & 0.0425 & 0.0534 \\
\hline \multirow[t]{2}{*}{ Morally acceptable } & Mean & 0.0158 & 0.0095 & 0.0220 \\
\hline & Standard deviation & 0.0429 & 0.0386 & 0.0473 \\
\hline \multirow{3}{*}{$\begin{array}{l}\text { Morally questionable-morally } \\
\text { acceptable }\end{array}$} & Mean & -0.0004 & -0.0074 & 0.0064 \\
\hline & Standard error & 0.0035 & - & - \\
\hline & Significance & 0.9140 & - & - \\
\hline
\end{tabular}

Note: This table shows the output of the paired sample test following the bootstrap process. The number of bootstrap samples used was 5000 .

TABLE 4: Risk-adjusted return measures: July 2004 to April 2019

\begin{tabular}{lccc}
\hline Variable & Sharpe ratio & Rank on Sharpe & Sortino ratio \\
\hline Morally questionable portfolio & 0.69 & 3 & 0.34 \\
Morally acceptable portfolio & 0.82 & 1 & 0.45 \\
RI Composite Index & 0.36 & 5 & 0.20 \\
EQBM & 0.71 & 2 & 0.37 \\
SWIX & 0.51 & 4 & 5 \\
\hline
\end{tabular}

RI, responsible investment; EQBM, equally weighted benchmark; SWIX, Shareholder Weighted Index.

Note: The Sharpe ratio and the Sortino ratio were annualised. The risk-free rate of return used was the annualised Alexander Forbes Short-Term Fixed Interest Rate Index, also known as the STeFI Index. 
The morally acceptable portfolio did, however, produce statistically significant risk-adjusted outperformance of the RI Composite Index, the EQBM and the SWIX over the full research period. By following an investment process focussed on highly rated RI shares, and excluding morally questionable and mining shares, it would have been possible to produce statistically significantly better riskadjusted returns compared to the RI Composite Index, an equally weighted strategy and investing in the SWIX. This outcome is similar to evidence presented by Kempf and Osthoff (2007) who showed that a strategy focussed on shares with high ESG ratings could produce positive excess returns. Furthermore, this result lends support to theoretical arguments about why RI strategies may produce outperformance. Theories such as the improved competitive advantage associated with positive business activities lead to long-term profitability.

The outperformance of the morally acceptable strategy over the RI Composite Index could be because of an improved filtering process. By specifically excluding any morally questionable and mining shares from the SRI constituents, a more focussed and concentrated 'responsible investing' strategy was formulated. The portfolio constructing methodology could also have impacted the observed results. The morally acceptable strategy had fewer shares on average and was equally weighted, whereas the RI Composite Index was more diversified and followed a market capitalisation weighting construction methodology.

\section{Performance during different market conditions}

Li et al. (2010) suggested that RI strategies are likely to perform differently in different market conditions; therefore, a single-period risk-adjusted return measure may be inadequate. Additionally, the stereotype that morally questionable companies are more resilient during periods of market stress leads Hoe et al. (2017) to suggest a sub-period analysis on sin share performance.

Table 6 presents the performance of morally questionable and morally acceptable shares relative to the benchmarks in two distinct periods. The first sub-period analysed (Panel A in Table 6) includes the global financial crisis and spans between October 2007 and March 2009. During this time, the SWIX produced an arithmetic mean monthly return of $-2.04 \%$. The second sub-period (Panel B in Table 6) includes the recovery period following the financial crisis (April 2009 to April 2010). During this period, the SWIX delivered an arithmetic mean monthly return of $3.54 \%$.

TABLE 5: Tests for significant differences in the Sharpe ratio.

\begin{tabular}{|c|c|c|c|c|}
\hline Variable & Morally acceptable portfolio & RI Composite Index & EQBM & SWIX \\
\hline \multicolumn{5}{|c|}{ Panel A: Sharpe ratio relative to morally questionable portfolio } \\
\hline Difference in Sharpe ratio & -0.13 & 0.33 & -0.01 & 0.18 \\
\hline$z$-score & -1.55 & 5.87 & -0.22 & 1.70 \\
\hline Significance & 0.13 & 0.00 & 0.82 & 0.09 \\
\hline Conclusion & No difference & $\begin{array}{l}\text { Morally questionable portfolio } \\
\text { outperforms }\end{array}$ & No difference & No difference \\
\hline \multicolumn{5}{|c|}{ Panel B: Sharpe ratio relative to morally acceptable portfolio } \\
\hline$z$-score & 1.55 & 6.99 & 1.97 & 2.77 \\
\hline Significance & 0.13 & 0.00 & 0.05 & 0.01 \\
\hline Conclusion & No difference & $\begin{array}{l}\text { Morally acceptable portfolio } \\
\text { outperforms }\end{array}$ & $\begin{array}{l}\text { Morally acceptable portfolio } \\
\text { outperforms }\end{array}$ & $\begin{array}{l}\text { Morally acceptable portfolio } \\
\text { outperforms }\end{array}$ \\
\hline
\end{tabular}

RI, responsible investment; EQBM, equally weighted benchmark; SWIX, Shareholder Weighted Index.

Note: This table shows the results of the Jobson and Korkie (1981) test with the Memmel (2003) correction calculated for differences in the Sharpe ratio. Panel A presents the results for the Sharpe ratio relative to the morally questionable portfolio Sharpe ratio. Panel B displays the results for the Sharpe ratio relative to the morally acceptable portfolio Sharpe ratio.

TABLE 6: Performance during different sub-periods.

\begin{tabular}{|c|c|c|c|c|}
\hline Variable & Annualised return $(\%)$ & Annualised standard deviation (\%) & Sharpe ratio & Rank \\
\hline \multicolumn{5}{|c|}{ Panel A: Performance in financial crisis period (October 2007 to March 2009) } \\
\hline Morally questionable portfolio & -13.96 & 26.14 & $-0.066 \dagger$ & 2 \\
\hline Morally acceptable portfolio & -17.38 & 23.92 & $-0.069 \dagger$ & 3 \\
\hline RI Composite Index & -24.21 & 27.15 & $-0.097 \dagger$ & 5 \\
\hline EQBM & -22.03 & 17.77 & $-0.059 \dagger$ & 1 \\
\hline SWIX & -23.71 & 21.40 & $-0.075 \dagger$ & 4 \\
\hline \multicolumn{5}{|c|}{ Panel B: Performance in recovery period (April 2009 to April 2010) } \\
\hline Morally questionable portfolio & 38.41 & 10.62 & 2.857 & 3 \\
\hline Morally acceptable portfolio & 46.23 & 13.81 & 2.763 & 4 \\
\hline RI Composite Index & 36.45 & 15.36 & 1.848 & 5 \\
\hline EQBM & 47.33 & 8.37 & 4.690 & 1 \\
\hline SWIX & 50.52 & 13.29 & 3.194 & 2 \\
\hline
\end{tabular}

RI, responsible investment; EQBM, equally weighted benchmark; SWIX, Shareholder Weighted Index.

Note: The table shows returns and risk-adjusted returns for two specific periods. Panel A shows the performance during the financial crisis (bear market) and Panel B shows the performance during the recovery period (bull market).

$\dagger$, Israelsen (2005) modified Sharpe ratio. 
From Panel A in Table 6 it can be seen that the morally questionable portfolio produced the best annualised return $(-13.96 \%)$ during the financial crisis. However, the best riskadjusted returns were produced by the EQBM. Following Chawana (2014), the Sharpe ratio for the crisis period was modified as suggested by Israelsen (2005). Using the traditional Sharpe ratio for periods when excess returns are negative may lead to incorrect rankings (Israelsen 2005). This is because of the way the Sharpe ratio changes with increases in standard deviation when excess returns are negative. To overcome this effect and achieve meaningful rankings of risk-adjusted returns, an exponent (excess return divided by absolute excess return) is added to the denominator of the Sharpe ratio. The morally questionable and morally acceptable portfolios produced similar risk-adjusted returns during the crisis period, and both outperformed the RI Composite Index and the SWIX. The results do not support the theory that morally questionable shares are more resilient during market downturns.

During the recovery period (Panel B in Table 6) the morally questionable portfolio lagged behind the morally acceptable portfolio, the EQBM and the SWIX, in terms of absolute returns. However, when accounting for risk, the Sharpe ratio of the morally questionable portfolio (2.857) was slightly higher than that of the morally acceptable portfolio (2.763), but lower than the SWIX (3.194). The EQBM produced the best risk-adjusted return during this period (4.690) and the RI Composite Index delivered the worst (1.848).

Chawana (2014) also showed that the SRI Index lagged behind conventional indices during the recovery after the financial crisis. The results shown in Panel B in Table 6 imply that although there is a cost in terms of risk-adjusted returns when investing in the RI composite during the recovery period, the more constrained morally acceptable strategy is not subject to the same opportunity cost. Table 7 reconciles the empirical results with the seven research hypotheses.

TABLE 7: Addressing the research hypotheses.

\begin{tabular}{|c|c|c|}
\hline Hypotheses & Description & Conclusion \\
\hline $\mathrm{H}_{01}$ & $\begin{array}{l}\text { There is no difference between the mean monthly } \\
\text { returns of the morally questionable portfolio and } \\
\text { the morally acceptable portfolio. }\end{array}$ & Fail to reject \\
\hline $\mathrm{H}_{02}$ & $\begin{array}{l}\text { There is no difference between the risk-adjusted } \\
\text { returns of the morally questionable portfolio and } \\
\text { the morally acceptable portfolio. }\end{array}$ & Fail to reject \\
\hline $\mathrm{H}_{03}$ & $\begin{array}{l}\text { There is no difference between the risk-adjusted } \\
\text { returns of the morally questionable portfolio and } \\
\text { the RI Composite Index. }\end{array}$ & Reject \\
\hline $\mathrm{H}_{04}$ & $\begin{array}{l}\text { There is no difference between the risk-adjusted } \\
\text { returns of the morally questionable portfolio and } \\
\text { the } \approx \text { SWIX. }\end{array}$ & Fail to reject \\
\hline $\mathrm{H}_{05}$ & $\begin{array}{l}\text { There is no difference between the risk-adjusted } \\
\text { returns of the morally questionable portfolio and } \\
\text { the EQBM. }\end{array}$ & Fail to reject \\
\hline $\mathrm{H}_{06}$ & $\begin{array}{l}\text { There is no difference between the risk-adjusted } \\
\text { returns of the morally acceptable portfolio and } \\
\text { the SWIX. }\end{array}$ & Reject \\
\hline $\mathrm{H}_{07}$ & $\begin{array}{l}\text { There is no difference between the risk-adjusted } \\
\text { returns of the morally acceptable portfolio and } \\
\text { the EQBM. }\end{array}$ & Reject \\
\hline
\end{tabular}

RI, responsible investment; EQBM, equally weighted benchmark; SWIX, Shareholder Weighted Index.
From Table 7, it can be seen that no evidence could be found of significant differences in the absolute or risk-adjusted returns between the morally questionable and morally acceptable portfolios. However, the morally questionable portfolio outperformed the RI Composite Index on a riskadjusted basis. The morally acceptable portfolio outperformed both the SWIX and the EQBM on a risk-adjusted basis.

\section{Conclusions and recommendations}

This study investigated the historical performance of a morally questionable oriented investment strategy relative to a morally acceptable strategy on the JSE. With the growth of RI, there could be a concern amongst socially and environmentally conscious investors about the opportunity costs involved in following a more sustainable investment approach. Essentially, the research question came down to: Is it better to be bad?

The main finding of the study was that morally questionable investing in South Africa does not produce risk-adjusted outperformance. No evidence could be found to support the various theories that predict outperformance of morally questionable shares listed on the JSE. The study confirmed previous studies on RI in South Africa, which showed underperformance of the FTSE/JSE RI Index. By suggesting an alternative (narrower) definition of RI, and contrasting it to morally questionable investing, it was shown that the non-financial benefits of RI do not come at an additional financial cost.

Another pertinent finding was that a different approach to morally questionable investing (morally acceptable investing) does not result in lower investment returns. The morally acceptable portfolio produced superior risk-adjusted returns relative to the RI Composite Index, the SWIX and an EQBM. This is an important result because it indicates to both retail and institutional investors that it is possible to follow a responsible and ethical investment approach without sacrificing investment returns. This outcome is particularly relevant for investors who prefer to invest in shares that have favourable ESG ratings.

The empirical evidence of this study may be of interest to asset managers drawn to creating RI strategies. It is recommended that closer attention is paid to the way the constituents of RI indices are selected. Perhaps the selection criteria are not strict enough. There could be additional financial and non-financial benefits by applying stricter ethical and environmental screening criteria. Reducing exposure to companies that contribute to environmental degradation has become more relevant as many economies have struggled to reduce carbon emissions in recent years. With the devastating environmental effects becoming more visible, climate change has become a prominent talking point on investor agendas.

For consultants to institutional investors, such as pension funds, the results of this study place the observed historical underperformance of RI in a different light. The results 
suggest closer attention should be given to selection criteria of responsible investing strategies, especially regarding the environmental aspects. Perhaps ESG ratings should be scrutinised more closely and not be taken at face value.

This study did not take into account the potential transaction costs involved in constructing and following either a morally questionable investment strategy or a morally acceptable investment strategy. Future researchers may incorporate portfolio turnover and transaction cost in their analyses. The research could potentially be expanded by employing a multi-factor model to determine whether the observed outperformance of morally acceptable shares is because of proven return drivers in the South African listed equity market.

The share level analysis applied in this study is in contrast to previous studies investigating the performance of RIs in South Africa. These studies were carried out on a fund level, or focussed on the returns of the RI Index. Not only is the study unique in terms of its focus on morally questionable investing in the country, but the approach followed to select morally questionable shares is also amended. The inclusion of coal mining shares in the definition of morally questionable shares, specifically, is arguably an improvement and is justified on the basis of the potential harm to both humans and the environment.

Given the increased importance of ethical and ESG considerations amongst investors, socially oriented investors could achieve returns in line with a morally questionable investment strategy and those of conventional benchmarks. These investors do not need to tolerate lower financial returns to derive the non-financial utility associated with RI. No evidence was found that a less morally conscious investor, following a morally questionable investing strategy, could realise higher riskadjusted returns. Stated differently, there is no risk premium available to the investor who is willing to shun morally oriented criteria. The study has shown that, in fact, it is not better to be bad.

\section{Acknowledgements Competing interests}

The authors have declared that no competing interest exists.

\section{Authors' contributions}

Both authors contributed equally to this work.

\section{Funding information}

This research received no specific grant from any funding agency in the public, commercial or not-for-profit sectors.

\section{Data availability statement}

The data that support the findings of this study are available from the corresponding author, J.P. Steyn, upon reasonable request.

\section{Disclaimer}

The views and opinions expressed in this article are those of the authors and do not necessarily reflect the official policy or position of any affiliated agency of the authors.

\section{References}

Barnett, M.L. \& Salomon, R.M., 2006, 'Beyond dichotomy: The curvilinear relationship between social responsibility and financial performance', Strategic Management Journal 27(11), 1101-1122. https://doi.org/10.1002/smj.557

Bauer, R., Derwall, J. \& Otten, R., 2007, 'The ethical mutual fund performance debate: New Evidence from Canada', Journal of Business Ethics 70(2), 111-124. https:// doi.org/10.1007/s10551-006-9099-0

Bauer, R., Koedijk, K. \& Otten, R., 2005, 'International evidence on ethical mutual fund performance and investment style', Journal of Banking and Finance 29(7) 1751-1767. https://doi.org/10.1016/j.jbankfin.2004.06.035

Bénabou, R. \& Tirole, J., 2010, 'Individual and corporate social responsibility', Economica 77(305), 1-19. https://doi.org/10.1111/j.1468-0335.2009.00843.x

Blitz, D. \& Fabozzi, F.J., 2017, 'Sin stocks revisited: Resolving the sin stock anomaly' The Journal of Portfolio Management 44(1), 105-111. https://doi.org/10.3905/ jpm.2017.44.1.105

Chang, C.E. \& Krueger, T.M., 2013, 'The VICEX Fund: Recent shortcomings of a longrun success story', Journal of Management and Sustainability 3(3), 131. https:// doi.org/10.5539/jms.v3n3p131

Chawana, M., 2014, 'Socially responsible investing returns: Evidence from South Africa, 2004-2012', Journal of Economic and Financial Sciences 7(1), 103-126. https://doi.org/10.4102/jef.v7i1.133

Derwall, J., Gunster, N., Bauer, R. \& Koedijk, K., 2004, 'The eco-efficiency premium puzzle', Financial Analyst Journal 61(2), 51-63. https://doi.org/10.2469/faj.v61. $\mathrm{n} 2.2716$

Derwall, J., Koedijk, K. \& Ter Horst, J., 2011, 'A tale of values-driven and profit-seeking social investors', Journal of Banking and Finance 35(8), 2137-2147. https://doi. org/10.1016/j.jbankfin.2011.01.009

Dimson, E., Marsh, P. \& Staunton, M., 2015, Global investment returns yearbook, Credit Suisse Research Institute, Zurich.

Durand, R.B., Koh, S. \& Limkriangkrai, M., 2013, 'Saints versus sinners. Does morality matter?', Journal of International Financial Markets, Institutions and Money 24(4), 166-183. https://doi.org/10.1016/j.intfin.2012.12.002

Efron, B. \& Tibshirani, R.J., 1993, An introduction to the bootstrap, Chapman \& Hall, New York, NY.

Fabozzi, F.J., Ma, K.C. \& Oliphant, B.J., 2008, 'Sin stock returns', The Journal of Portfolio Management 35(1), 82-94. https://doi.org/10.3905/JPM.2008.35.1.82

Fama, E.F. \& French, K.R., 2015, 'A five-factor asset pricing model', Journal of Financial Economics 116(1), 1-22. https://doi.org/10.1016/j.jfineco.2014.10.010

Fauver, L. \& McDonald (IV), M.B., 2014, 'International variation in sin stocks and its effects on equity valuation', Journal of Corporate Finance 25(1), 173-187. https:// doi.org/10.1016/j.jcorpfin.2013.11.017

Frost, G., Jones, S., Loftus, J. \& Van der Laan, S., 2005, 'A survey of sustainability reporting practices of Australian reporting entities', Australian Accounting Review 15(35), 89-96. https://doi.org/10.1111/j.1835-2561.2005.tb00256.x

Fu, S. \& Shan, L., 2009, 'Corporate equality and equity prices: Doing well while doing good?', SSRN, viewed 26 January 2019, from http://dx.doi.org/10.2139/ ssrn.1368422.

Giamporcaro, S. \& Pretorius, L., 2012, 'Sustainable and responsible investment in South Africa: A limited adoption of environmental criteria', Investment Analysts Journal 75(41), 17-35. https://doi.org/10.1080/10293523.2012.11082541

Gil-Bazo, J., Ruiz-Verdú, P. \& Santos, A.A.P., 2010, 'The performance of socially responsible mutual funds: The role of fees and management companies', Journa of Business Ethics 94(2), 243-263. https://doi.org/10.1007/s10551-009-0260-4

Girard, E.C., Rahman, H. \& Stone, B.A., 2007, 'Socially responsible investments', The Journal of Investing 16(1), 96-110. https://doi.org/10.3905/joi.2007.681827

Gladysek, O. \& Chipeta, C., 2012, 'The impact of socially responsible investment index constituent announcements on firm price: Evidence from the JSE', South African Journal of Economic and Management Sciences 15(4), 429-439. https://doi. org/10.4102/sajems.v15i4.236

Hamilton, S., Jo, H. \& Statman, M., 1993, 'Doing well while doing good? The investment performance of socially responsible mutual funds', Financial Analysts Journa 49(6), 62-66. https://doi.org/10.2469/faj.v49.n6.62

Herringer, A., Firer, C. \& Viviers, S., 2009, 'Key challenges facing the socially responsible investment (SRI) sector in South Africa', Investment Analysts Journal 38(70), 11-26. https://doi.org/10.1080/10293523.2009.11082511 
Hoe, S., Liu, L., Diltz, J.D. \& Ogunc, A.K., 2017, 'Sinners and saints: An alternative approach to evaluating the investment performance of sin funds versus sinless funds', Journal of Accounting and Finance 17(6), 109-116.

Hoepner, A.G.F. \& Zeume, S., 2014, 'Fiduciary duty and sin stocks: Is vice really nice?', in James P. Hawley (ed.), Handbook of institutional investment and fiduciary duty, pp. 181-206, Cambridge University Press, Cambridge.

Hong, H. \& Kacperczyk, M., 2009, 'The price of sin: The effects of social norms on markets', Journal of Financial Economics 93(1), 15-36. https://doi.org/10.1016/j. jfineco.2008.09.001

Israelsen, C.L., 2005, 'A refinement to the sharpe ratio and information ratio', Journal of Asset Management 5(6), 423-427. https://doi.org/10.1057/palgrave. jam. 2240158

Jarque, C.M. \& Bera, A.K., 1980, 'Efficient tests for normality, homoscedasticity and serial independence of regression residuals', Economics Letters 6(3), 255-259. https://doi.org/10.1016/0165-1765(80)90024-5

Jo, H., Saha, T., Sharma, R. \& Wright, S., 2010, 'Socially responsible investing vs. vice investing', in Academic and business research institute conference, viewed 16 March 2019, from http://citeseerx.ist.psu.edu/viewdoc/download?doi=10.1.1.620.6429.

Jobson, J.D. \& Korkie, B.M., 1981, 'Performance hypothesis testing with the sharpe and treynor measures', The Journal of Finance 36(4), 889-908. https://doi. org/10.1111/j.1540-6261.1981.tb04891.x

JSE (Johannesburg Stock Exchange), 2004, SRI index: Background and selection criteria viewed 01 April 2006, from https://www.jse.co.za/content/JSEIndexSelectionCrite rialtems $/ 2004$-Background $\% 20$ and $\% 20$ criteria $\% 20$.pdf.

JSE (Johannesburg Stock Exchange), 2014, FTSE-JSE shareholder weighted indices brochure, viewed 11 June 2019, from https://www.jse.co.za/services/marketdata/indices/ftse-jse-africa-index-series/shareholder-weighted.

JSE (Johannesburg Stock Exchange), 2019, Responsible investment index, viewed 11 June 2019, from https://www.jse.co.za/services/market-data/indices/ftse-jseafrica-index-series/responsible-investment-index.

Kempf, A. \& Osthoff, P., 2007, 'The effect of socially responsible investing on portfolio performance', European Financial Management 13(5), 908-922. https://doi. org/10.1111/j.1468-036X.2007.00402.X

Kitzmueller, M. \& Shimshack, J., 2012, 'Economic perspectives on corporate social responsibility', Journal of Economic Literature 50(1), 51-84. https://doi. org/10.1257/jel.50.1.51

Knoepfel, I., 2001, 'Dow Jones sustainability group index: A global benchmark for corporate sustainability', Corporate Environmental Strategy 8(1), 6-15. https:// doi.org/10.1016/S1066-7938(00)00089-0

Li, H., Cheung, A. \& Roca, E., 2010, 'Socially responsible investment, good and bad times', SSRN, viewed 07 March 2019, from http://dx.doi.org/10.2139/ssrn.1662788.

Lins, K.V., Servaes, H. \& Tamayo, A., 2017, 'Social capital, trust, and firm performance: The value of corporate social responsibility during the financial crisis', The Journal of Finance 72(4), 1785-1824. https://doi.org/10.1111/jofi.12505

Lobe, S. \& Walkshäusl, C., 2016, 'Vice versus virtue investing around the world', Review of Managerial Science 10(2), 303-344. https://doi.org/10.1007/s11846-014$0147-3$

Margolis, J.D., Elfenbein, H.A. \& Walsh, J.P., 2009, 'Does it pay to be good... and does it matter? A meta-analysis of the relationship between corporate social and financial performance', SSRN, viewed 07 March 2019, from http://dx.doi.org/10.2139/ ssrn.1866371.

Memmel, C., 2003, 'Performance hypothesis testing with the Sharpe ratio', SSRN, viewed 04 February 2019, from https://ssrn.com/abstract=412588.

Merton, R.C., 1987, 'A simple model of capital market equilibrium with incomplete information', The Journal of Finance 42(3), 483-510. https://doi.org/10.1111/ j.1540-6261.1987.tb04565.x

Nofsinger, J. \& Varma, A., 2014, 'Socially responsible funds and market crises', Journal of Banking and Finance 48(4), 180-193. https://doi.org/10.1016/j.jbankfin.2013.12.016
PRI (Principles for Responsible Investment), 2019, About the PRI, viewed 19 June 2019, from https://www.unpri.org/about-the-pri.

Ratshomo, K. \& Nembahe, R., 2016, South African coal sector report, viewed 03 July 2019, from http://www.energy.gov.za/files/media/explained/South-African-CoalSector-Report.pdf.

Renneboog, L., Ter Horst, J. \& Zhang, C., 2008, 'Socially responsible investments: Institutional aspects, performance, and investor behavior', Journal of Banking and Finance 32(9), 1723-1742. https://doi.org/10.1016/j.jbankfin.2007.12.039

Richey, G.M., 2016, 'Sin is in: An alternative to socially responsible investing?', The Journal of Investing 25(2), 136-143. https://doi.org/10.3905/joi.2016.25.2.136

Richey, G.M., 2017, 'Fewer reasons to sin: A five-factor investigation of vice stock returns', Managerial Finance 43(9), 1016-1033. https://doi.org/10.1108/MF-092016-0268

Riedl, A. \& Smeets, P., 2017, 'Why do investors hold socially responsible mutual funds?', The Journal of Finance 72(6), 2505-2550. https://doi.org/10.1111/ jofi.12547

Salaber, J.M., 2007, 'The determinants of sin stock returns: Evidence on the European market', SSRN, viewed 30 October 2019, from https://ssrn.com/abstract=1071746.

Salaber, J.M., 2009, 'Sin stock returns over the business cycle', SSRN, viewed 30 October 2019, from http://ssrn.com/abstract=1443188.

Schröder, M., 2007, 'Is there a difference? The performance characteristics of SRI equity indices', Journal of Business Finance and Accounting 34(1-2), 331-348. https://doi.org/10.1111/j.1468-5957.2006.00647.x

Shank, T., Manullang, D. \& Hill, R., 2005, “'Doing well while doing good” revisited: A study of socially responsible firms' short-term versus long-term performance', Managerial Finance 31(8), 33-46. https://doi.org/10.1108/03074350510769794

Shleifer, A. \& Vishny, R.W., 1997, 'The limits of arbitrage', The Journal of Finance 52(1), 35-55. https://doi.org/10.1111/j.1540-6261.1997.tb03807.x

Sortino, F. \& Van der Meer, R., 1991, 'Downside risk', Journal of Portfolio Management 17(4), 27-31. https://doi.org/10.3905/jpm.1991.409343

Sparkes, R., 2001, 'Ethical investment: Whose ethics, which investment?', Business Ethics: A European Review 10(3), 194-205. https://doi.org/10.1111/14678608.00233

Sparkes, R. \& Cowton, C.J., 2004, 'The maturing of socially responsible investments: A review of the developing link with corporate social responsibility', Journal of Business Ethics 52(1), 45-57. https://doi.org/10.1023/B:BUSI.0000033106. Business
43260.99

Statman, M., 2000, 'Socially responsible mutual funds', Financial Analysts Journal 56(3), 30-39. https://doi.org/10.2469/faj.v56.n3.2358

Statman, M., 2006, 'Socially responsible indexes: Composition, performance, and tracking error', Journal of Portfolio Management 32(3), 100-109. https://doi. org/10.3905/jpm.2006.628411

Statman, M. \& Glushkov, D., 2009, 'The wages of social responsibility', Financial Analysts Journal 65(4), 33-46. https://doi.org/10.2469/faj.v65.n4.5

Vide, T., 2016, 'Does it pay to be good? An analysis of vice and virtue stock performance in the Eurozone', Journal of Banking and Financial Economics 6(2), 113-125.

Viviers, S. \& Els, G., 2017, 'Responsible investing in South Africa: Past, present and future', African Review of Economics and Finance 9(1), 122-155.

Viviers, S. \& Firer, C., 2013, 'Responsible investing in South Africa - A retail perspective', Journal of Economic and Financial Sciences 6(1), 217-242. https://doi. org/10.4102/jef.v6i1.285

Walley, N. \& Whitehead, B., 1994, 'It's not easy being green', Harvard Business Review 72(3), 46-52.

Webster, A, 1995, Applied statistics for business and economics, Irwin Professional Publishing, Dallas, TX.

World Health Organisation, 2017, Mercury and health, viewed 15 May 2019, from https://www.who.int/en/news-room/fact-sheets/detail/mercury-and-health. 